\title{
Serum 25-hydroxyvitamin D and biochemical markers of bone metabolism in patients with juvenile idiopathic arthritis
}

\author{
R.V. Munekata, M.T.R.A. Terreri, O.A.B. Peracchi, C. Len, M. Lazaretti-Castro, \\ R.O.S. Sarni and M.O.E. Hilário
}

Unidade de Reumatologia Pediátrica, Divisão de Alergia, Imunologia Clínica e Reumatologia, Departamento de Pediatria, Universidade Federal de São Paulo, São Paulo, SP, Brasil

\begin{abstract}
Our objective was to evaluate the concentrations of serum 25-hydroxyvitamin D [25(OH)D], serum calcium, serum phosphorus, alkaline phosphatase, and parathormone (PTH) in patients with polyarticular juvenile idiopathic arthritis (JIA) and to associate them with disease duration and activity, bone mineral density and use of medications. In a cross-sectional and controlled study, 30 patients with polyarticular JIA were evaluated and compared to 30 healthy individuals matched for age and gender. Clinical status, anthropometry, laboratory markers in both patients and controls, and bone mineral density, only in the patients, were measured. Of the 30 patients included in the study, $23(76.7 \%)$ were female and 16 (53.3\%) non-Caucasian; mean age was 14 years (range $=4$ to 20 years). Mean disease duration was 5 years (range $=1$ to 12 years). The mean concentrations of serum albumin-corrected calcium $(9.04 \pm 0.41 \mathrm{mg} / \mathrm{dL})$ and alkaline phosphatase $(153.3 \pm 100.1 \mathrm{IU})$ were significantly lower in patients with JIA than in controls $(P<0.0001$ and $P=0.001$, respectively). No differences in $25(\mathrm{OH}) \mathrm{D}, \mathrm{PTH}$ or serum phosphorus were observed between JIA and control subjects. Regarding 25(OH)D concentration, 8 patients $(26.7 \%)$ and 5 controls $(16.7 \%)$ had $25(\mathrm{OH}) \mathrm{D}$ concentrations compatible with deficiency (lower than $20 \mathrm{ng} / \mathrm{mL}$ ) and 14 patients $(46.7 \%)$ and 18 controls $(60 \%)$ had concentrations compatible with insufficiency $(20-32 \mathrm{ng} / \mathrm{mL})$. These values were not associated with disease activity, use of medications or bone mineral density. We observed a high frequency of $25(\mathrm{OH}) \mathrm{D}$ insufficiency and deficiency in the study sample. The compromised bone metabolism emphasizes the importance of follow-up of JIA patients.
\end{abstract}

Key words: Juvenile idiopathic arthritis; Serum vitamin D deficiency; Calcium; Alkaline phosphatase

\section{Introduction}

Juvenile idiopathic arthritis (JIA) is the most common chronic rheumatic disease of childhood in developed countries and an important cause of short- and long-term disability.

The effects of vitamin $D$ have been studied in experimental models of autoimmunity. In humans, there are some difficulties in establishing a direct relationship between vitamin $D$ deficiency and an increase in the frequency of rheumatic diseases, considering the limitations of available studies, such as different cut-offs used and small subject samples (1).

Although intake is not the best method for the assessment of the nutritional status of vitamin $D$, a higher intake of this vitamin was found to be inversely related to the development of rheumatoid arthritis in a cohort study of 29,368 women (2). In patients with rheumatoid arthritis, available results suggest a high frequency of vitamin $D$ insufficiency or deficiency (3-9) and show that vitamin D supplementation in subjects with active disease may relieve the symptoms and reduce inflammation (10).

Studies performed in healthy children and adolescents have shown lower serum concentrations of 25-hydroxyvitamin $\mathrm{D}[25(\mathrm{OH}) \mathrm{D}]$ at frequencies ranging from 9 to $62 \%$ (11-13). However, only a few studies have assessed the serum concentrations of $25(\mathrm{OH}) \mathrm{D}$ in children and adolescents with JIA (14-17).

The aim of the present study was to determine the serum concentrations of $25(\mathrm{OH}) \mathrm{D}$, serum calcium, serum phosphorus, alkaline phosphatase, and parathormone (PTH) in patients with polyarticular JIA and to associate them or not with disease activity and duration, bone mineral density and use of medications (glucocorticoids and hydroxychloroquine) and supplements containing vitamin $\mathrm{D}$ and calcium.

Correspondence: M.T.R.A. Terreri, Rua Ipê, 112, Apto. 111, 04022-005 São Paulo, SP, Brasil. Fax: +55-11-5579-1590. E-mail: teterreri@terra.com.br 


\section{Patients and Methods}

In a cross-sectional and controlled study, 30 patients of a total of 50 patients with polyarticular JIA were evaluated according to the criteria of the International League of Associations for Rheumatology (ILAR) (18). The patients were followed at the Pediatric Rheumatology Clinic from September to November 2008. Twenty patients were excluded due either to other chronic diseases interfering with the calcium metabolism, or because they could not perform bone density measurements due to their stature or they did not consent to participate in the study.

Thirty healthy individuals, matched for gender and age to the patients, not using supplements containing vitamin $\mathrm{D}$ or calcium were included as controls.

The demographic, clinical and treatment data obtained with a standardized questionnaire were collected from the patients' charts. To assess if the disease was active, we used the remission criteria described in previous papers $(19,20)$.

The anthropometric assessment included weight and height measurements using as reference those proposed by the World Health Organization (WHO) (21-23). Pubertal development was determined as recommended by Marshall and Tanner (24).

Blood samples were collected from patients and controls after a 12-h fast for the following laboratory tests: serum phosphorus and serum albumin-corrected calcium by a colorimetric method with reactant molibidate and arsenazo, respectively, and alkaline phosphatase measured by an enzyme activity method with reactant $p$ nitrophenyl phosphate (Biochemical Analyzer Olympus AU640, USA). Urinary calcium and creatinine were determined in the patients by a colorimetric method using a specified apparatus. All biochemical analyses of patients and controls were performed from September to November 2008, corresponding to the Brazilian spring months. Since there is seasonal variability in $25(\mathrm{OH}) \mathrm{D}$, we opted, as done in other studies, to collect the samples in the spring.

Serum $25(\mathrm{OH}) \mathrm{D}$ was determined in 2009 by electrochemiluminescence immunoassay using the commercial kit Elecsys 25(OH)D3 (USA) and serum intact PTH was determined by immunofluorimetry using the same kit. Reference 25(OH)D values below $20 \mathrm{ng} / \mathrm{mL}$ indicate deficiency, values between 20 and $32 \mathrm{ng} / \mathrm{mL}$ indicate insufficiency, and values above $32 \mathrm{ng} / \mathrm{mL}$ are considered to be ideal (25). The normal range for PTH is 15 to $65 \mathrm{pg} / \mathrm{mL}$.

The bone mineral density of the spine (L1-L4) was measured by dual-energy X-ray absorptiometry (DXA) using a Lunar $^{\mathrm{TM}}$ DPX-MD plus densitometer (GE-Lunar Radiation Corporation, USA) equipped with pediatric software (version 8.5). Bone mineral density was adjusted for height by the method of Khan et al. (26).
All statistical calculations were done using the statistical software SPSS 18.0. The chi-square test or, when indicated, the Fisher test was applied to evaluate the association between dichotomous variables. The normality of continuous variables was established by the Kolmogorov-Smirnov test and is reported as means $\pm S D$. The Student $t$-test was used to compare groups regarding the variables under study. Pearson's correlation coefficient was used for the quantitative variables with normal distribution. An $\alpha<5 \%$ was adopted $(P<0.05)$.

An informed consent form was signed by all patients and controls and/or their legal guardians. The Ethics Committee of the Universidade Federal de São Paulo, Hospital São Paulo (CEP No. 0178/09) approved the study protocol.

\section{Results}

Table 1 shows the characteristics of the study group. In the JIA group, the mean age at diagnosis was 9 years (3 to 16 years) and the mean disease duration was 5 years (1 to 12 years); 12/30 (40\%) patients had active disease at the time of evaluation. Six (20\%) patients had positive rheumatoid factor.

No differences in serum $25(\mathrm{OH}) \mathrm{D}, \mathrm{PTH}$ or phosphorus concentrations were observed between the JIA and control groups (Table 2). The mean concentrations of serum albumin-corrected calcium and alkaline phospha-

Table 1. Demographic characteristics, nutritional status, and pubertal stage of patients with juvenile idiopathic arthritis.

\begin{tabular}{lrc}
\hline Variables & \multicolumn{1}{c}{ JIA } & Controls \\
\hline Females & $23(76.7)$ & $23(76.7)$ \\
Age at evaluation (range) & $14(4-20)$ & $14(4-19)$ \\
Ethnic origin & & \\
$\quad$ Caucasian & $14(46.7)$ & $19(63.3)$ \\
$\quad$ Non-Caucasian & $16(53.3)$ & $11(36.7)$ \\
BMI Z score & & \\
$\quad$ Eutrophic & $20(66.7)$ & $30(100)$ \\
$\quad$ Non-eutrophic & $10(33.3)$ & 0 \\
$\quad$ Malnutrition & $5(16.6)$ & 0 \\
$\quad$ Overweight & $3(10.0)$ & 0 \\
$\quad$ Obesity & $2(6.7)^{*}$ & 0 \\
S/A Z score & & \\
Low height & $5(17.9)$ & 0 \\
$\quad$ Adequate height & $23(82.1)$ & $28(100)^{\mathrm{a}}$ \\
Pubertal stage & & \\
$\quad$ Prepubertal stage & $6(20.0)$ & $6(20.0)$ \\
Pubertal stage & $24(80.0)$ & $24(80.0)$ \\
\hline
\end{tabular}

Data are reported as number with percent in parentheses for 30 patients in each group. $\mathrm{JIA}=$ juvenile idiopathic arthritis; $\mathrm{BMI}=$ body mass index; $\mathrm{S} / \mathrm{A}=$ stature for age. ${ }^{*} \mathrm{P}<0.05$ compared to controls (chi-square test). ${ }^{\mathrm{a}} \mathrm{Tw}$ watients were older than 19 years. 
Table 2. Serum concentrations of $25(\mathrm{OH}) \mathrm{D}$, PTH, calcium, phosphorus, and alkaline phosphatase of patients with juvenile idiopathic arthritis.

\begin{tabular}{lcc}
\hline & JIA & Controls \\
\hline 25(OH)D (ng/mL) & $25.70 \pm 8.65$ & $26.92 \pm 7.62$ \\
PTH $(\mathrm{pg} / \mathrm{mL})$ & $31.21 \pm 12.35$ & $30.04 \pm 15.63$ \\
Albumin-corrected & $9.04 \pm 0.41^{*}$ & $9.48 \pm 0.48$ \\
calcium $(\mathrm{mg} / \mathrm{dL})$ & & \\
Serum phosphorus $(\mathrm{mg} / \mathrm{dL})$ & $4.45 \pm 0.61$ & $4.17 \pm 0.86$ \\
Alkaline phosphatase $(\mathrm{IU})$ & $153.3 \pm 100.1^{*}$ & $285.2 \pm 169.9$
\end{tabular}

Data are reported as means \pm SD for 30 patients in each group. $\mathrm{JIA}=$ juvenile idiopathic arthritis; $25(\mathrm{OH}) \mathrm{D}=25$-hydroxyvitamin $\mathrm{D} ; \mathrm{PTH}=$ parathormone. ${ }^{*} \mathrm{P}<0.05$ compared to control group (Student $t$-test).

tase were significantly lower in the JIA patients than in the controls (Table 2). All but 2 patients had calciuria/ creatinuria ratios within the normal range.

Regarding serum 25(OH)D concentrations, 8 patients $(26.7 \%)$ and 5 controls $(16.7 \%)$ had values compatible with deficiency $(<20 \mathrm{ng} / \mathrm{mL})$ and 14 patients $(46.7 \%)$ and 18 controls $(60 \%)$ had values compatible with insufficiency (20-32 ng/mL). Three patients with deficiency and 6 with insufficiency of $25(\mathrm{OH}) \mathrm{D}$ had active disease at the time of evaluation.

Only 1 patient (3.3\%) and 1 control (3.3\%) had elevated PTH levels $(>65 \mathrm{pg} / \mathrm{mL})$, with $25(\mathrm{OH}) \mathrm{D}$ concentrations of 24.4 and $39.9 \mathrm{ng} / \mathrm{mL}$, respectively.

$25(\mathrm{OH}) \mathrm{D}$ concentrations were not different in relation to ethnicity $(P=0.896), Z$ body mass index $(P=0.111)$, $Z$ stature/age $(P=0.136)$, or pubertal stage $(P=0.398)$.

In the JIA group, $3 / 30(10 \%)$ patients were taking chloroquine, $11 / 30(36.7 \%)$ were taking a calcium supplement and 6/30 (20\%) were taking vitamin D. No patients were on glucocorticoids and/or biphosphonate at the time of evaluation.

There was no association between $25(\mathrm{OH}) \mathrm{D}$ concentrations and disease activity $(P=0.737)$, use of vitamin $D$ supplements $(P=0.124)$, use of chloroquine $(P=0.661)$ or bone mineral density $(P=0.350)$ in the JIA patients (Student $t$-test).

Three patients had low bone mass density for age; of those, 1 had insufficient 25(OH)D concentration and 1 had deficiency. Nine patients had osteopenia; of those, 5 had 25(OH)D insufficiency and 2 had deficiency. One patient did not perform the DXA. We did not find any correlations between low bone mass and disease duration or corticotherapy.

Neither the laboratory tests nor the disease duration correlated with serum 25(OH)D concentrations: PTH $(r=$ $-0.020, P=0.877)$; serum albumin-corrected calcium $(r=0.057, P=0.765)$; serum phosphorus $(r=-0.030, P$ $=0.818)$; alkaline phosphatase $(r=0.109, P=0.408)$; calciuria/creatinuria ratio $(r=-0.155, P=0.414)$; disease duration $(r=0.079, P=0.680)$.

\section{Discussion}

In this study involving patients with JIA, we found a high frequency of 25(OH)D insufficiency and deficiency; however, these findings did not differ significantly between patients and controls. Hillman et al. (14), also assessing serum concentrations of $25(\mathrm{OH}) \mathrm{D}$, did not report any difference between JIA patients and controls. Potential explanations for the high frequency of deficiency/insufficiency in both groups may be the frequent use of sunblocks (27), dietary and life style changes with consequent adiposity and overweight (28) and season when the analyses were performed $(29,30)$.

It is important to emphasize that vitamin $D$ deficiency is a current public health issue that has been increasing, including in healthy individuals of all ages in developed and developing countries (11-13). These findings recently motivated a revision of the recommendations for vitamin D (31).

There is no consensus regarding the ideal serum concentrations of $25(\mathrm{OH}) \mathrm{D}$, especially in the pediatric group, which makes it difficult to compare the results from different studies. In the present study, we decided to use the cut-offs suggested by Grant and Holick (25) as recommended in the revision by the Institute of Medicine (31).

Another important aspect is the kind of assay used for $25(\mathrm{OH}) \mathrm{D}$ analysis, which may lead to a false diagnosis of vitamin $D$ deficiency. The electrochemiluminescence immunoassay with the Elecsys Roche's kit for polyclonal immunoassay, used in the present study, showed in previous studies a good correlation with the method considered as gold standard, i.e., liquid chromatography mass spectrometry $(32,33)$.

An inverse association between PTH and 25(OH)D concentrations has been demonstrated in adults and the persistent increase in PTH levels may result in hyperparathyroidism secondary to the vitamin deficiency $(11,12,29)$. In children, however, this association has not been frequently observed, a fact that limits the use of PTH as a functional marker for vitamin D deficiency (34). We found only one patient $(3.3 \%)$ with elevated PTH in spite of the high frequency of vitamin D insufficiency/deficiency.

Our study showed lower levels of serum albumincorrected calcium and alkaline phosphatase in patients with JIA compared to controls. Those alterations do not seem to be of clinical significance. A previous study showed significantly lower osteocalcin and alkaline phosphatase concentrations in individuals with JIA compared to controls, suggesting reduced bone formation (14). Lower calcium concentrations in the JIA group, with no difference in $25(\mathrm{OH}) \mathrm{D}$ concentrations may be explained by the reduced capacity for mineral absorption described in children with arthritis (17). A study in animal 
models with induced arthritis revealed a reduction in $1,25(\mathrm{OH})_{2} \mathrm{D}$ receptors, with a consequent reduction in calcium absorption (35).

We did not find an association between $25(\mathrm{OH}) \mathrm{D}$ concentrations with either disease activity or duration. In adults with rheumatoid arthritis there are multiple risk factors for vitamin $D$ deficiency and there is evidence that the deficiency is associated with the activity $(4,7)$ and severity of the disease (5,7-9).

Pelajo et al. (36) found a similar frequency of reduced vitamin $D$ in their study with 154 JIA patients, which was also not related to disease activity. They observed an association between 25(OH)D concentrations and age, ethnicity, body mass index, and season of the year, but not with vitamin $D$ intake.

A recent publication evaluating the vitamin $D$ binding protein isoforms showed that some subgroups are related to the extension of arthritis (37).

The use of supplements containing vitamin $D$ was not associated with serum $25(\mathrm{OH}) \mathrm{D}$ concentrations, with low values even in patients receiving supplementation. There is still no consensus on the ideal supplement dose of vitamin D for patients with JIA. Hillman et al. (17) observed an increase in serum calcium and $25(\mathrm{OH}) \mathrm{D}$ concentrations, with no impact on bone mineral gain, with the administration of $2000 \mathrm{IU}$ vitamin D3/day in children with arthritis. In our clinic, vitamin D supplementation at a dose of 200 to $800 \mathrm{IU}$ is recommended in association with 500 to $1000 \mathrm{mg}$ calcium for patients with a risk of bone mass loss (active inflammatory disease and chronic use of glucocorticoids).

\section{References}

1. Pelajo CF, Lopez-Benitez JM, Miller LC. Vitamin D and autoimmune rheumatologic disorders. Autoimmun Rev 2010; 9: 507-510, doi: 10.1016/j.autrev.2010.02.011.

2. Merlino LA, Curtis J, Mikuls TR, Cerhan JR, Criswell LA, Saag KG. Vitamin $D$ intake is inversely associated with rheumatoid arthritis: results from the lowa Women's Health Study. Arthritis Rheum 2004; 50: 72-77, doi: 10.1002/art. 11434.

3. Kerr GS, Sabahi I, Richards JS, Caplan L, Cannon GW, Reimold $A$, et al. Prevalence of vitamin $D$ insufficiency/ deficiency in rheumatoid arthritis and associations with disease severity and activity. J Rheumatol 2011; 38: 53-59, doi: 10.3899/jrheum.100516.

4. Vieira VM, Hart JE, Webster TF, Weinberg J, Puett R, Laden $F$, et al. Association between residences in U.S. northern latitudes and rheumatoid arthritis: A spatial analysis of the Nurses' Health Study. Environ Health Perspect 2010; 118: 957-961, doi: 10.1289/ehp.0901861.

5. Braun-Moscovici $Y$, Toledano K, Markovits D, Rozin A, Nahir AM, Balbir-Gurman A. Vitamin D level: is it related to disease activity in inflammatory joint disease? Rheumatol Int 2011; 31: 493-499, doi: 10.1007/s00296-009-1251-6.

6. Haque UJ, Bartlett SJ. Relationships among vitamin D,
Regarding the medications used for JIA treatment, only 3 patients were on hydroxychloroquine at the time of inclusion, with no interference with vitamin D concentrations. In the literature, the effect of hydroxychloroquine on vitamin D metabolism is still controversial (38).

DXA showed that three $(10 \%)$ of the 30 patients had low bone mass density for age. A cross-sectional study in the literature evaluating bone mass in children and young adults with JIA showed lower bone mass in the patients compared to healthy individuals (39). A recently published prospective study involving patients with JIA showed reduced bone mass density at the initial evaluation compared to controls (40).

There are some limitations to the present study, namely the small sample size, the cross-sectional model used that does not allow causality evaluations, and no DXA in the control group. Furthermore, the method applied for the determination of 25(OH)D concentrations may be questioned, as well as our cut-off values.

We observed serum insufficient/deficient 25(OH)D concentrations in a large number of patients, although with no relation to disease activity or duration, use of medications and vitamin D supplementation or bone mineral density. These findings, associated with the impairment of bone metabolism observed in our patients even in the absence of alterations in bone mineral density, emphasize the importance of the follow-up of JIA patients.

\section{Acknowledgments}

\author{
Research supported by FAPESP (\#08/57420-3).
}

disease activity, pain and disability in rheumatoid arthritis. Clin Exp Rheumatol 2010; 28: 745-747.

7. Craig SM, Yu F, Curtis JR, Alarcon GS, Conn DL, Jonas B, et al. Vitamin $D$ status and its associations with disease activity and severity in African Americans with recent-onset rheumatoid arthritis. J Rheumatol 2010; 37: 275-281, doi: 10.3899/jrheum.090705.

8. Rossini M, Maddali Bongi S, La Montagna G, Minisola G, Malavolta N, Bernini L, et al. Vitamin D deficiency in rheumatoid arthritis: prevalence, determinants and associations with disease activity and disability. Arthritis Res Ther 2010; 12: R216, doi: 10.1186/ar3195.

9. Cutolo M, Otsa K, Laas K, Yprus M, Lehtme R, Secchi ME, et al. Circannual vitamin $d$ serum levels and disease activity in rheumatoid arthritis: Northern versus Southern Europe. Clin Exp Rheumatol 2006; 24: 702-704.

10. Andjelkovic Z, Vojinovic J, Pejnovic N, Popovic M, Dujic A, Mitrovic $D$, et al. Disease modifying and immunomodulatory effects of high dose 1 alpha $(\mathrm{OH})$ D3 in rheumatoid arthritis patients. Clin Exp Rheumatol 1999; 17: 453-456.

11. Kumar J, Muntner P, Kaskel FJ, Hailpern SM, Melamed ML. Prevalence and associations of 25-hydroxyvitamin D deficiency in US children: NHANES 2001-2004. Pediatrics 
2009; 124: e362-e370, doi: 10.1542/peds.2009-0051.

12. Gordon CM, Feldman HA, Sinclair L, Williams AL, Kleinman PK, Perez-Rossello J, et al. Prevalence of vitamin D deficiency among healthy infants and toddlers. Arch Pediatr Adolesc Med 2008; 162: 505-512, doi: 10.1001/ archpedi.162.6.505.

13. Peters BS, dos Santos LC, Fisberg M, Wood RJ, Martini LA. Prevalence of vitamin D insufficiency in Brazilian adolescents. Ann Nutr Metab 2009; 54: 15-21, doi: 10.1159/ 000199454

14. Hillman L, Cassidy JT, Johnson L, Lee D, Allen SH. Vitamin $\mathrm{D}$ metabolism and bone mineralization in children with juvenile rheumatoid arthritis. J Pediatr 1994; 124: 910-916, doi: 10.1016/S0022-3476(05)83179-8.

15. Pepmueller PH, Cassidy JT, Allen SH, Hillman LS. Bone mineralization and bone mineral metabolism in children with juvenile rheumatoid arthritis. Arthritis Rheum 1996; 39: 746757, doi: 10.1002/art.1780390506.

16. Falcini $F$, Ermini M, Bagnoli $F$. Bone turnover is reduced in children with juvenile rheumatoid arthritis. J Endocrinol Invest 1998; 21: 31-36.

17. Hillman LS, Cassidy JT, Chanetsa F, Hewett JE, Higgins BJ, Robertson JD. Percent true calcium absorption, mineral metabolism, and bone mass in children with arthritis: effect of supplementation with vitamin D3 and calcium. Arthritis Rheum 2008; 58: 3255-3263, doi: 10.1002/art.23809.

18. Petty RE, Southwood TR, Manners P, Baum J, Glass DN, Goldenberg J, et al. International League of Associations for Rheumatology classification of juvenile idiopathic arthritis: second revision, Edmonton, 2001. J Rheumatol 2004; 31 : 390-392.

19. Wallace CA, Ruperto N, Giannini E. Preliminary criteria for clinical remission for select categories of juvenile idiopathic arthritis. J Rheumatol 2004; 31: 2290-2294.

20. Machado C, Ruperto N. Consensus in pediatric rheumatology part I - criteria definition of inactive disease and remission in juvenile idiopathic arthritis/juvenile rheumatoid arthritis. Rev Bras Reumatol 2012; 45: 9-13.

21. Physical status: the use and interpretation of anthropometry. Report of a WHO Expert Committee. World Health Organization Tech Rep Ser 1995; 854: 1-452.

22. de Onis M, Onyango AW, Borghi E, Siyam A, Nishida C, Siekmann J. Development of a WHO growth reference for school-aged children and adolescents. Bull World Health Organ 2007; 85: 660-667, doi: 10.2471/BLT.07.043497.

23. Obesity: preventing and managing the global epidemic. Report of a WHO consultation. World Health Organization Tech Rep Ser 2000; 894: i-xii-1-253.

24. Marshall WA, Tanner JM. Variations in pattern of pubertal changes in girls. Arch Dis Child 1969; 44: 291-303, doi: 10.1136/adc.44.235.291.

25. Grant WB, Holick MF. Benefits and requirements of vitamin D for optimal health: a review. Altern Med Rev 2005; 10: 94111.

26. Khan AA, Bachrach L, Brown JP, Hanley DA, Josse RG, Kendler DL, et al. Standards and guidelines for performing central dual-energy $\mathrm{X}$-ray absorptiometry in premenopausal women, men, and children. J Clin Densitom 2004; 7: 51-64, doi: $10.1385 / J C D: 7: 1: 51$.
27. Looker AC, Pfeiffer CM, Lacher DA, Schleicher RL, Picciano MF, Yetley EA. Serum 25-hydroxyvitamin D status of the US population: 1988-1994 compared with 2000-2004. Am J Clin Nutr 2008; 88: 1519-1527, doi: 10.3945/ajcn.2008.26182.

28. Arnberg K, Ostergard M, Madsen AL, Krarup H, Michaelsen $\mathrm{KF}$, Molgaard C. Associations between vitamin D status in infants and blood lipids, body mass index and waist circumference. Acta Paediatr 2011; 100: 1244-1248, doi: 10.1111/j.1651-2227.2011.02273.x.

29. Gordon CM, DePeter KC, Feldman HA, Grace E, Emans SJ. Prevalence of vitamin D deficiency among healthy adolescents. Arch Pediatr Adolesc Med 2004; 158: 531537, doi: 10.1001/archpedi.158.6.531.

30. Houghton LA, Szymlek-Gay EA, Gray AR, Ferguson EL, Deng $X$, Heath AL. Predictors of vitamin D status and its association with parathyroid hormone in young New Zealand children. Am J Clin Nutr 2010; 92: 69-76, doi: 10.3945/ajcn.2009.29055.

31. Abrams SA. Dietary guidelines for calcium and vitamin D: a new era. Pediatrics 2011; 127: 566-568, doi: 10.1542/peds. 2010-3576.

32. Leino A, Turpeinen $U$, Koskinen $P$. Automated measurement of 25-OH vitamin D3 on the Roche Modular E170 analyzer. Clin Chem 2008; 54: 2059-2062, doi: 10.1373/ clinchem.2008.111732.

33. Connell AB, Jenkins N, Black M, Pasco JA, Kotowicz MA, Schneider HG. Overreporting of vitamin $D$ deficiency with the Roche Elecsys Vitamin D3 (25-OH) method. Pathology 2011; 43: 368-371, doi: 10.1097/PAT.0b013e328346431c.

34. Thacher TD, Clarke BL. Vitamin D insufficiency. Mayo Clin Proc 2011; 86: 50-60, doi: 10.4065/mcp.2010.0567.

35. Langman CB, Ford KK, Pachman LM, Glorieux F. Vitamin $D$ metabolism in rats with adjuvant-induced arthritis. J Bone Miner Res 1990; 5: 905-913, doi: 10.1002/jbmr. 5650050903.

36. Pelajo CF, Lopez-Benitez JM, Kent DM, Price LL, Miller LC, Dawson-Hughes B. 25-Hydroxyvitamin D levels and juvenile idiopathic arthritis: Is there an association with disease activity? Rheumatol Int 2011; doi: 10.1007/s00296-0112287-y.

37. Gibson DS, Newell K, Evans AN, Finnegan S, Manning G, Scaife $\mathrm{C}$, et al. Vitamin $\mathrm{D}$ binding protein isoforms as candidate predictors of disease extension in childhood arthritis. J Proteomics 2012; 75: 5479-5492, doi: 10.1016/ j.jprot.2012.06.024.

38. Huisman AM, White KP, Algra A, Harth M, Vieth R, Jacobs $\mathrm{JW}$, et al. Vitamin D levels in women with systemic lupus erythematosus and fibromyalgia. J Rheumatol 2001; 28: 2535-2539.

39. Celiker R, Bal S, Bakkaloglu A, Ozaydin E, Coskun T, Cetin $A$, et al. Factors playing a role in the development of decreased bone mineral density in juvenile chronic arthritis. Rheumatol Int 2003; 23: 127-129.

40. Stagi S, Masi L, Capannini S, Cimaz R, Tonini G, MatucciCerinic $\mathrm{M}$, et al. Cross-sectional and longitudinal evaluation of bone mass in children and young adults with juvenile idiopathic arthritis: the role of bone mass determinants in a large cohort of patients. J Rheumatol 2010; 37: 1935-1943, doi: 10.3899/jrheum.091241. 